\title{
Analogous pleiotropic effects of insecticide resistance genotypes in peach-potato aphids and houseflies
}

\author{
SP Foster ${ }^{1}$, S Young 2 , MS Williamson ${ }^{2}$, I Duce ${ }^{3}$, I Denholm ${ }^{1}$ and GJ Devine ${ }^{1}$ \\ ${ }^{1}$ Plant and Invertebrate Ecology Division, Rothamsted Research, Harpenden AL5 2JQ, UK; ${ }^{2 B}$ Biological Chemistry Division, Rothamsted \\ Research, Harpenden AL5 2JQ, UK; ${ }^{3}$ School of Life and Environmental Sciences, University of Nottingham, University Park Nottingham \\ NG7 2RD, UK
}

\begin{abstract}
We show that single-point mutations conferring target-site resistance $(k d r)$ to pyrethroids and DDT in aphids and houseflies, and gene amplification conferring metabolic resistance (carboxylesterase) to organophosphates and carbamates in aphids, can have deleterious pleiotropic effects on fitness. Behavioural studies on peach-potato aphids showed that a reduced response to alarm pheromone was associated with both gene amplification and the $k d r$ target-site mutation. In this species, gene amplification was
\end{abstract}

also associated with a decreased propensity to move from senescing leaves to fresh leaves at low temperature. Housefly genotypes possessing the identical $k d r$ mutation were also shown to exhibit behavioural differences in comparison with susceptible insects. In this species, resistant individuals showed no positional preference along a temperature gradient while susceptible genotypes exhibited a strong preference for warmer temperatures.

Heredity (2003) 91, 98-106. doi:10.1038/sj.hdy.6800285

Keywords: pleiotropy; insecticide resistance; point mutation; gene amplification; behaviour

\section{Introduction}

In the peach-potato aphid, Myzus persicae (Hemiptera: Aphididae), gene amplification leads to the overproduction of carboxylesterases that enhance the detoxification of insecticidal esters such as organophosphates (OPs) and carbamates (Devonshire and Moores, 1982; Field et al, 1988). In the same species, a point mutation of a voltagegated sodium channel gene confers cross-resistance to pyrethroids and DDT (knockdown resistance or kdr) (Martinez-Torres et al, 1999). This latter mutation is common to many pyrethroid-resistant insect species, including Musca domestica (Diptera: Muscidae) (Vais et al, 2001).

It has long been proposed that the majority of insecticide-resistant organisms should show some differential survival in comparison with 'wildtype' organisms (eg Crow, 1957). However, despite the extensive literature on the subject, there are relatively few empirical studies that confirm that investment in such adaptations exacts a cost (Minkoff and Wilson, 1992; Carriere et al, 1994, 1995; Yamamoto et al, 1995; Chevillon et al, 1997; Alyokhin and Ferro, 1999; Boivin et al, 2001). Some authors have failed to reveal any detrimental effects of insecticide resistance (Follett et al, 1993; Tang et al, 1997, 1999; Baker et al, 1998) and some have shown such organisms to be even more successful than their susceptible counterparts in the absence of insecticides

Correspondence: GJ Devine, Plant and Invertebrate Ecology Division, Rothamsted Research, Harpenden AL5 2JQ, UK;

E-mail: greg.devine@bbsrc.ac.uk

Received 27 September 2002; accepted 12 February 2003
(Omer et al, 1992; Bloch and Wool, 1994; White and Bell, 1995; Mason, 1998; Haubruge and Arnaud, 2001). In other studies, some measures of fitness have been negatively affected, others positively (Brewer and Trumble, 1991) and different strains of insect, exhibiting resistance to the same compound, can show opposite associations (Chevillon et al, 1997; Hollingsworth et al, 1997; Oppert et al, 2000).

It is possible that the lack of any clear pattern in the literature results from the fact that evolutionary pathways can compensate for fitness disadvantages through the development of modifier genes (McKenzie and O'Farrell, 1993; Charpentier and Fournier, 2001) or through the replacement of mutant alleles by less costly ones (Guillemaud et al, 1998), but it may also reflect the fact that fitness costs are generally investigated by comparing biological parameters such as development times (Boots and Begon, 1993; Baker et al, 1998; Boivin et al, 2001), fecundity (Hollingsworth et al, 1997; Brewer et al, 1999; Boivin et al, 2001), and intrinsic rates of growth (Yamamoto et al, 1995) usually under optimal laboratory conditions. By concentrating purely on such obviously detrimental parameters and by failing to consider suboptimal conditions (stressful environments in which fitness differentials are at a premium), subtle pleiotropic effects on biology or behaviour are often overlooked (McKenzie, 1996). Examples of behavioural effects that have been shown to be correlated with resistance are therefore rare but include mating disruption and oviposition preference in dieldrin-resistant Anopheline mosquitoes (Rowland, 1991a,b), mating success in Bacillus thuringiensis (Bt)-resistant diamondback moths (Groeters et al, 1993), response to alarm pheromone in 
aphids (Foster et al, 1999), and overwintering success in Bt-resistant pink bollworms (Carriere et al, 2001), insecticide-resistant aphids (Foster et al, 1996, 1997) and blowflies (McKenzie, 1993). There is little understanding of the genotypic basis of these resistance-associated traits, but some may be examples of true pleiotropies, whereby one gene influences more than one aspect of an organism's phenotype. In pest-management terms, such effects clearly have the potential to exert a large influence on the selection and dynamics of genes conferring insecticide resistance.

The work reported here expands upon previous research on clones of $M$. persicae that showed behavioural effects to be correlated with elevated titres of carboxylesterases and with the presence or absence of $k d r$ (Foster et al, 1996, 1997, 1999). It also reports on behavioural characteristics associated with $k d r$ in the housefly ( $M$. domestica). We present strong evidence that resistant genotypes may suffer pleiotropic fitness costs in the absence of insecticides, and that in the case of the $k d r$ mutation, these are often likely to be identified in behavioural assays because of the effect of the resistant mutation on nerve function.

\section{Methods and materials}

\section{M. persicae clones and diagnosis of resistance}

In total, $22 \mathrm{M}$. persicae clones, collected from England and mainland Europe, showing different combinations of $k d r$ and esterase resistance (Table 1) were used in the

Table 1 Myzus persicae clones assessed in leaf deterioration and alarm pheromone response bioassays

\begin{tabular}{lccl}
\hline Clone & $\begin{array}{c}\text { Esterase resistance } \\
\text { phenotype }\end{array}$ & $\begin{array}{c}k d r \text { genotype } \\
(k d r)^{\mathrm{b}}\end{array}$ & \multicolumn{1}{c}{ Origin } \\
\hline $\mathrm{US1L}$ & $\mathrm{S}$ & $\mathrm{SS}$ & England 1974 \\
$1076 \mathrm{~A}$ & $\mathrm{~S}$ & $\mathrm{SS}$ & England 1992 \\
$4090 \mathrm{~A}$ & $\mathrm{~S}$ & $\mathrm{SS}$ & Scotland 2000 \\
$4106 \mathrm{~A}$ & $\mathrm{~S}$ & $\mathrm{SS}$ & Scotland 2000 \\
$405 \mathrm{D}$ & $\mathrm{R}_{1}$ & $\mathrm{SS}$ & England 1977 \\
$1260 \mathrm{R}^{\ddagger}$ & $\mathrm{R}_{2}$ & $\mathrm{SS}$ & Greece 1994 \\
$2165 \mathrm{~B}$ & $\mathrm{R}_{2}$ & $\mathrm{SS}$ & England 1997 \\
$2141 \mathrm{~A}^{\ddagger}$ & $\mathrm{R}_{2}$ & $\mathrm{SS}$ & England 1997 \\
$800 \mathrm{~F}^{\ddagger}$ & $\mathrm{R}_{3}$ & $\mathrm{SS}$ & Italy 1978 \\
$1190 \mathrm{~A}^{\ddagger}$ & $\mathrm{R}_{3}$ & $\mathrm{SS}$ & Spain 1993 \\
$2160 \mathrm{D}$ & $\mathrm{R}_{1}$ & $\mathrm{SR}$ & England 1997 \\
$1302 \mathrm{M}^{\ddagger}$ & $\mathrm{R}_{2}$ & $\mathrm{SR}$ & England 1996 \\
$100 \mathrm{~N}$ & $\mathrm{R}_{2}$ & $\mathrm{SR}$ & England 1993 \\
$108 \mathrm{~T}$ & $\mathrm{R}_{3}$ & $\mathrm{SR}$ & England 1993 \\
$2161 \mathrm{C}^{\ddagger}$ & $\mathrm{R}_{3}$ & $\mathrm{SR}$ & England 1997 \\
$2169 \mathrm{G}^{\ddagger}$ & $\mathrm{R}_{3}$ & $\mathrm{SR}$ & England 1997 \\
T1 $^{\ddagger}$ & $\mathrm{R}_{2}$ & $\mathrm{RR}$ & England 1975 \\
$794 \mathrm{~J}^{\ddagger}$ & $\mathrm{R}_{3}$ & $\mathrm{RR}$ & England 1982 \\
$2043 \mathrm{~B}^{\ddagger}$ & $\mathrm{R}_{3}$ & $\mathrm{RR}$ & England 1996 \\
$2165 \mathrm{C}^{\ddagger}$ & $\mathrm{R}_{3}$ & $\mathrm{RR}$ & England 1997 \\
$794 \mathrm{~J}(\mathrm{rev})^{\mathrm{c} \ddagger}$ & $\mathrm{R}_{3}$ genotype/S phenotype & $\mathrm{RR}$ & England 1994 \\
$923 \mathrm{~A}^{\mathrm{c}}$ & $\mathrm{R}_{3}$ genotype/S phenotype & $\mathrm{RR}$ & England 1990 \\
& & & \\
\hline & & &
\end{tabular}

All clones were used in studies on low-temperature movement. A subset of these, marked $\ddagger$, was used in alarm pheromone studies. aS: susceptible, $R_{1}$ : moderately resistant, $R_{2}$ : highly resistant, $R_{3}$ : extremely resistant forms.

benotype determined by direct sequencing of sodium channel fragments amplified from single aphids.

cRevertant clone carrying unexpressed, highly amplified E4 genes, that is phenotypically indistinguishable from esterase-susceptible clones with respect to esterase production. experiments. All aphids were maintained at $21 \pm 1^{\circ} \mathrm{C}$ on single excised leaves of Chinese cabbage (Brassica rapa $\mathrm{L}$. var. pekinensis) in small perspex boxes under a 16:8 L:D regime. In $M$. persicae, $\mathrm{kdr}$ is caused by a single-point mutation (L1014P) in the para-type sodium channel gene. The genotypes of individual clones were determined by DNA sequencing of PCR-amplified para gene fragments as described previously (Martinez-Torres et al, 1999). Genotypes were scored as either susceptible homozygote $(k d r-S S)$, heterozygote $(k d r-S R)$, or resistant homozygote ( $k d r$-RR) with the latter two being associated with resistance to pyrethroids and DDT (Martinez-Torres et al, 1999). Esterase levels, representing increasing levels of resistance $\left(S, R_{1}, R_{2}\right.$, and $R_{3}$ ) to OPs and carbamates (Devonshire et al, 1982, 1986) were based on the relative activities of immunocaptured E4 or FE4 carboxylesterases, the enzyme responsible for esterase-based insecticide resistance (Devonshire et al, 1986). None of these clones carried a third insecticide resistance mechanism known in $M$. persicae, termed modified acetylcholinesterase (MACE) (Moores et al, 1994).

\section{Response of $M$. persicae clones to synthetic alarm pheromone}

The aphid alarm pheromone $(E)$ - $\beta$-farnesene is released from cornicle secretions exuded by aphids when they are physically disturbed, for example by foraging predators or parasitoids. Aphid response to synthetic alarm pheromone, applied at a wide range of concentrations, was assessed in the absence of insecticides in seven separate experiments. For each aphid clone tested, six first instar nymphs were obtained from laboratory stocks and grown to adulthood (in two small perspex boxes containing three aphids per clone). These first-generation $\left(G_{1}\right)$ adults were removed after they had produced approximately $30 \mathrm{G}_{2}$ offspring per box (normally after about 10 days). The $\mathrm{G}_{2}$ aphids were grown to adulthood and transferred, using a fine paintbrush, to inverted $2 \mathrm{~cm}$ diameter Chinese cabbage discs (four $\mathrm{G}_{2}$ adult apterae per disc) held on $1.1 \%$ agar inside plastic tubs. The plastic tubs were left at $21 \pm 1{ }^{\circ} \mathrm{C}$ overnight to allow the aphids to settle and produce nymphs. The adults were removed next morning leaving synchronised cohorts of settled offspring on each disc. Each replicate cohort was then assessed for response to alarm pheromone by applying a $1 \mu \mathrm{l}$ droplet (ranging from 0.0001 to $10 \mathrm{mg}(E)$ - $\beta$-farnesene $\mathrm{ml}^{-1}$ in hexane) to the central part of each leaf disc with a fine-needle syringe. Aphid behaviour was observed for 2 min using a binocular microscope (preliminary experiments showed that this period is sufficient for all responses to occur). Nymphs that withdrew their stylets and walked away were scored as responders. Control treatments with $1 \mu \mathrm{l}$ droplets of hexane alone did not stimulate aphid movement. Each replicate batch of nymphs was tested once and then discarded.

\section{Movement of $M$. persicae clones from deteriorating leaves at low temperature}

Aphid movement from deteriorating excised Chinese cabbage leaves onto oilseed rape plants (Brassica napus L.) was assessed in seven separate experiments at low temperature (using one replicate per clone per experiment). Prior to each experiment, $M$. persicae clones were reared at $21 \pm 1^{\circ} \mathrm{C}$ under a $16: 8 \mathrm{~L}: \mathrm{D}$ regime in small 
perspex boxes. In each replicate, four young apterous adults were allowed to produce nymphs over 2 days on an excised Chinese cabbage leaf. All adults and surplus nymphs were then removed before the boxes, each containing 50 first/second instar nymphs, were transferred to $10 \pm 1{ }^{\circ} \mathrm{C}$ (8:16 L:D regime) for $24 \mathrm{~h}$ temperature acclimation. Clones were then allocated (one replicate per plant) to 5-week-old plants (maintained under a $6 \pm 1^{\circ} \mathrm{C}, 8: 16 \mathrm{~L}: \mathrm{D}$ regime) arranged in a single row using an incomplete block design. Movement from each deteriorated excised leaf was assessed 5 days after it had been attached by the petiole and apex to the upper face of a healthy oilseed rape leaf using $4 \mathrm{~cm}$ clips. Numbers of aphids that moved to any part of the plant or remained on the deteriorated excised leaf were recorded at the end of each experiment.

\section{M. domestica strains and maintenance}

The origin of all housefly strains used is detailed in Table 2 . They were reared at $28 \pm 1^{\circ} \mathrm{C}$. Adults were kept in aluminium cages $(0.3 \mathrm{~m} \times 0.15 \mathrm{~m} \times 0.15 \mathrm{~m})$ with open ends; one covered with polythene netting, one with a terylene sleeve. Adults were fed on $20 \%$ sugar solution and encouraged to oviposit on cotton wool plugs soaked in milk. Eggs and young larvae were used to 'seed' a larval medium (milk, yeast, bran, and water in the ratio 2:2:3:7 by weight). Pupae were collected by flotation, gathered in a sieve, and transferred to the aluminium cages. The $k d r$ (mutation L1014P) and super-kdr (mutation M918 T) genotypes were scored by DNA sequencing of PCR-amplified para sodium channel fragments from adult flies (Williamson et al, 1996).

\section{Bioassays on $M$. domestica}

All populations were tested for their responses to technical DDT and the pyrethroid deltamethrin. Serial dilutions were made up in acetone, and $1 \mu$ l of solution was topically applied to each fly. Control groups were treated with acetone alone and each group consisted of 10-15 female flies. Treated flies were kept in plastic containers with cotton wool soaked in sugar solution. Mortality was scored after $48 \mathrm{~h}$. Each dose was tested against three groups and bioassays were conducted at least twice.

Temperature gradient studies on $M$. domestica An aluminium sheet, $24 \mathrm{~cm}$ long and encased in a perspex cage (see Figure 1) was used to create a temperature gradient. One end of the sheet was kept in an ice bucket in which the ice was continuously replaced

Table 2 Origins of housefly strains

\begin{tabular}{llll}
\hline Strain & Date & \multicolumn{1}{c}{$k d r$ genotype } & \\
\hline Cooper & c.1950 & $k d r$-susceptible & Origin \\
USA1 & c.1995 & Susceptible & UK \\
USA2 & c.1995 & Susceptible & USA \\
$530^{\mathrm{b}}$ & 1987 & $k d r$ and super- $k d r^{\mathrm{a}}$ & USA \\
$579 \mathrm{~b}$ & 1977 & $k d r^{\mathrm{a}}$ & Denmark \\
$690 \mathrm{ab}$ & 1984 & Unknown & Italy \\
$213 \mathrm{ab}$ & 1957 & $k d r$ and super $-k d r^{\mathrm{b}}$ & Denmark \\
& & & Sweden \\
\hline
\end{tabular}

aAll strains were homozygous for the alleles listed.

bDerived by repeated backcrossing of $k d r$ or super- $k d r$ flies to the Cooper strain and reselecting for resistance (Farnham et al, 1987).

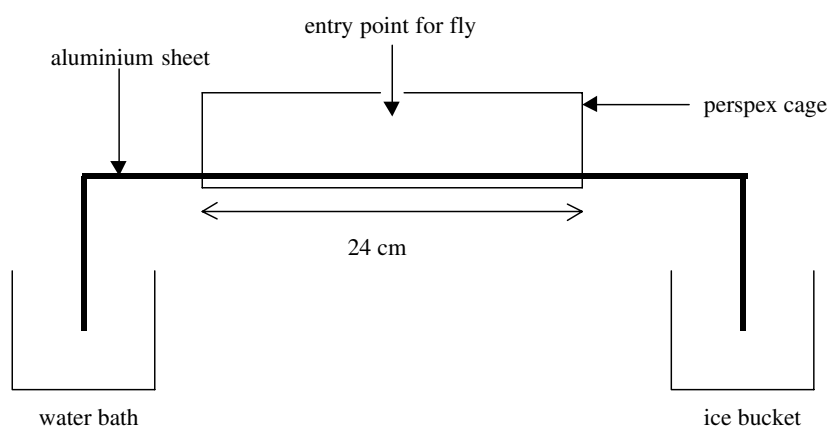

Figure 1 Apparatus for measuring temperature preference in houseflies.

to create a temperature of $19 \pm 1.5^{\circ} \mathrm{C}$ at the $0 \mathrm{~cm}$ mark. The opposite end was immersed in a water bath to give a temperature of $29 \pm 1^{\circ} \mathrm{C}$ at the $24 \mathrm{~cm}$ mark. The quarter points of the aluminium sheet $(6,12$, and $18 \mathrm{~cm})$ were $21.5 \pm 1^{\circ} \mathrm{C}, 24 \pm 1^{\circ} \mathrm{C}$, and $26.5 \pm 1^{\circ} \mathrm{C}$, respectively.

All experiments were carried out in a well-ventilated, temperature-controlled room $\left(26 \pm 1^{\circ} \mathrm{C}\right)$ under infrared light to remove any visual cues. Individual female flies were kept in a refrigerator until they were sluggish and easy to manipulate. These were then dropped into the perspex case above the midpoint of the aluminium sheet. Each fly was given $30 \mathrm{~s}$ to recover before its position was noted. If a fly had not recovered in that time, it was removed and another released in its place. Between each observation, the aluminium sheet was swabbed with ethanol to remove any semio-chemical cues that could influence the movement of other flies. The orientation of the aluminium plate was also reversed between observations so that any bias resulting from the position of the apparatus was removed. All experiments were conducted between 12:00 and 18:00 $\mathrm{h}$ to standardise the part of the diel cycle that individuals were experiencing. Several strains were tested during each experimental period to randomise effects peculiar to that day (eg age of flies, barometric pressure, etc).

Once each fly had recovered, its position was noted 1, 5, 10, 15, and $20 \mathrm{~min}$ after introduction. After $20 \mathrm{~min}$, observations were terminated. In total, 12-16 adult females were used for each strain, spread across at least three separate assay dates, and results were pooled for analysis.

\section{Data analyses}

Generalised linear models were fitted, using probit transformation, to the proportions of aphids in each replicate responding to alarm pheromone or moving from deteriorating leaves, including effects for clones, experiments, $k d r$ genotype, and mean carboxylesterase activity (esterase level).

Housefly bioassays were combined for probit analysis (POLO-PC, 1984). Comparisons of the proportions moving to the warmest quarter of the temperature gradient were analysed using a generalised linear model with a binomial distribution.

\section{Results}

Response of $M$. persicae clones to synthetic alarm pheromone

Aphid response increased with higher alarm pheromone concentrations for all three $k d r$ genotypes. Fitting a 


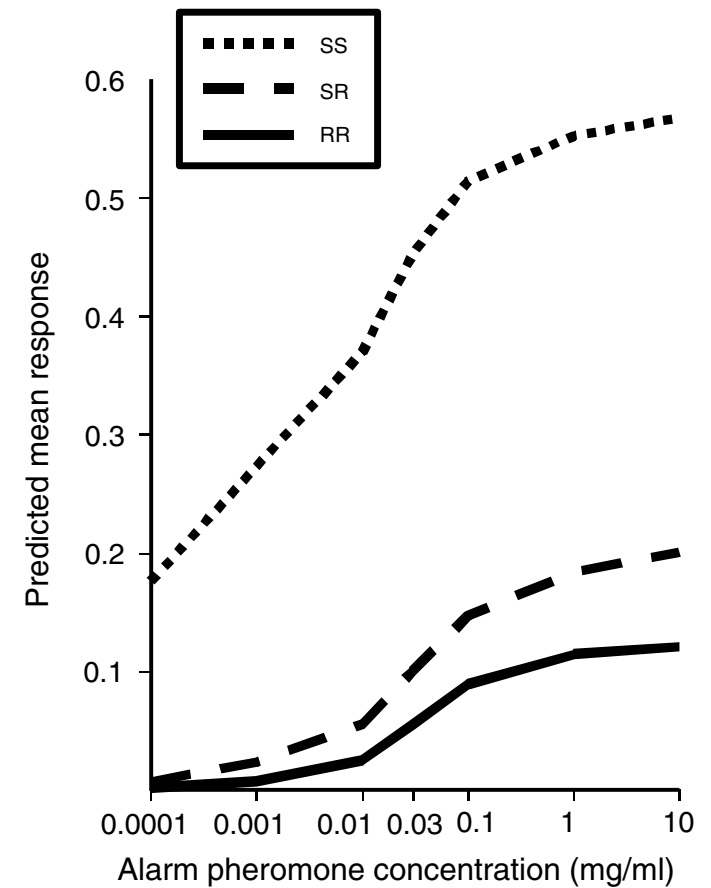

Figure 2 Predicted mean response to alarm pheromone of Myzus persicae clones with $k d r$-SS, -SR, and -RR genotypes (clones within each genotype pooled).

generalised linear model with a probit link and adjusting for esterase level and concentration effects, the tendency to respond was strongly associated with $k d r$ genotype (Figure 2); the significance of differences between genotypes being as follows; SS vs SR, difference: 1.00, $t_{715}=8.6, P<0.001$; SS vs RR, difference: $1.75, t_{715}=14.7$, $P<0.001 ; \quad$ SR $v s \quad$ RR, difference: $0.75, t_{715}=6.6$, $P<0.001$.

Furthermore, esterase resistance (adjusted for $k d r$ effects and excluding the revertant clone) was inversely associated with pheromone response (Figures 3 and 4 ) (slope: -1.31 , SE $0.13, P<0.001$ ). The revertant clone, 794Jrev, was not significantly different from the clone $794 \mathrm{~J}$ that had retained expression of its highly amplified (esterase- $\mathrm{R}_{3}$ level) $\mathrm{E} 4$ genes $\left(t_{715}=1.7, P=0.09\right)$.

\section{Movement of $M$. persicae clones from deteriorating} leaves at low temperature

After adjusting for esterase level, the mean proportions $( \pm S E)$ of aphids moving from deteriorating leaves in each genotype, for $k d r$-susceptible homozygotes ( $k d r$-SS), $k d r$-heterozygotes $(k d r$-SR), and $k d r$-resistant homozygotes ( $k d r$-RR) were, respectively, $0.48 \pm 0.03,0.54 \pm 0.04$, and $0.52 \pm 0.03$. There were no significant differences between these three genotypes ( $k d r$-SR vs $k d r$-SS: $t_{76}=1.25 P=0.22, k d r$-SS vs $k d r-R R: t_{76}=0.87, P=0.39$, $k d r$-SR vs $k d r$-RR: $\left.t_{76}=0.38, P=0.71\right)$. Thus, movement from deteriorating leaves was not associated with $k d r$ genotype (Figure 5).

There was, however, a significant inverse relation between the tendency to move and esterase level (overall slope: -0.28 , SE $0.12, P=0.027$ ) (Figure 5). This relation was also apparent within the $k d r$-SS and $k d r$-SR categories (SS slope: -0.62 , SE $0.20, P=0.003$; SR slope: -1.18 , SE $0.55, P=0.036$ ). However, it was not apparent within the $k d r$-RR category, because all clones in this

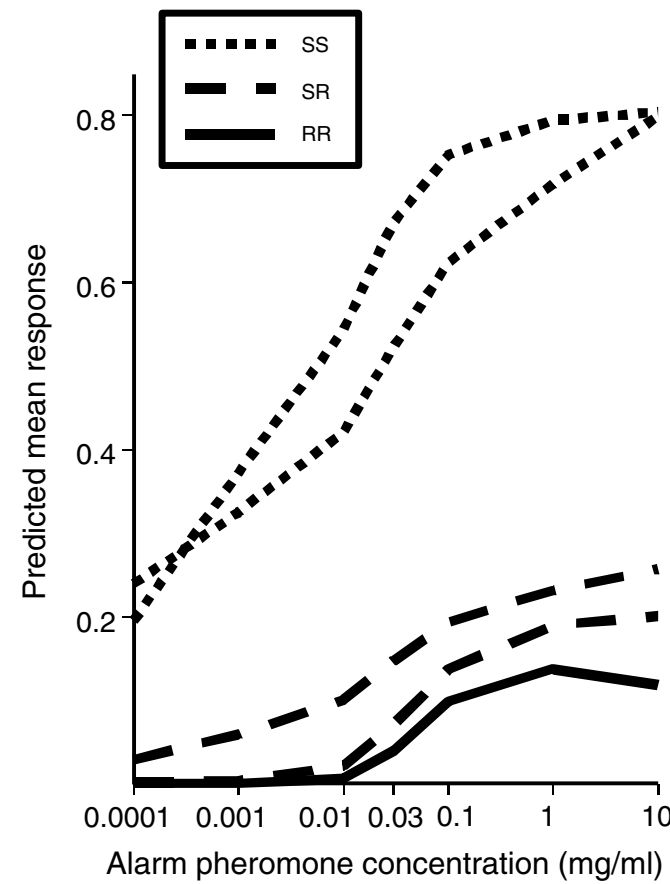

Figure 3 Predicted mean response to alarm pheromone of esterase$\mathrm{R}_{2}$ Myzus persicae clones with $k d r$-SS, -SR, and -RR genotypes (individual clones shown).

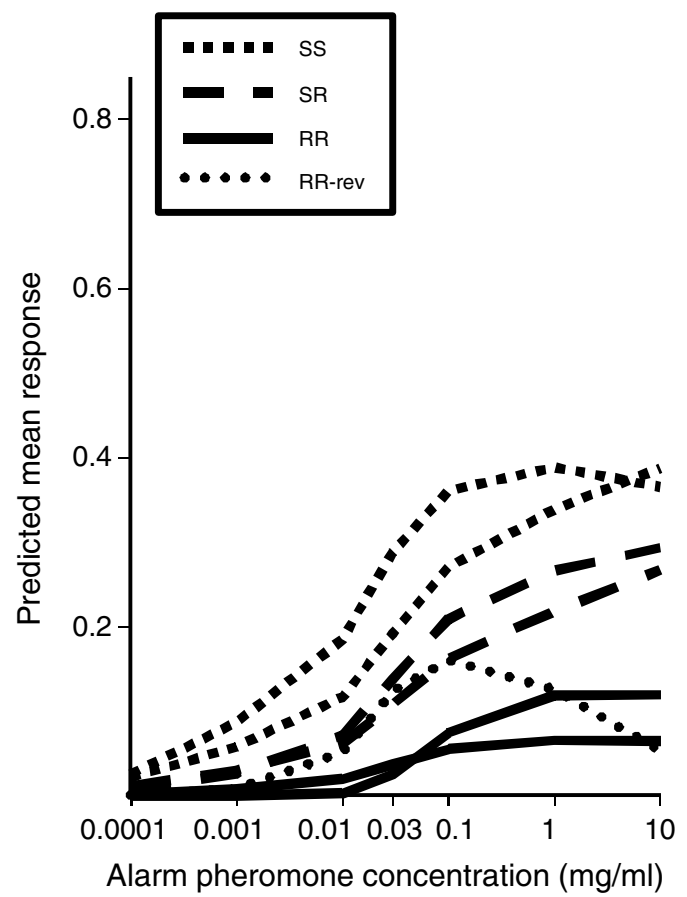

Figure 4 Predicted mean response to alarm pheromone of esterase$\mathrm{R}_{3}$ Myzus persicae clones with $k d r$-SS, -SR, and -RR genotypes (individual clones shown).

instance (with the exception of the two esterase-revertant clones) had very high esterase levels (RR slope: 0.08 , SE $0.17, P=0.65$ ). The two esterase-revertant clones (having the genotype for $R_{3}$ amplified esterase, but the susceptible phenotype (Field et al, 1989) segregated with other high-esterase clones, in that they exhibited a limited 

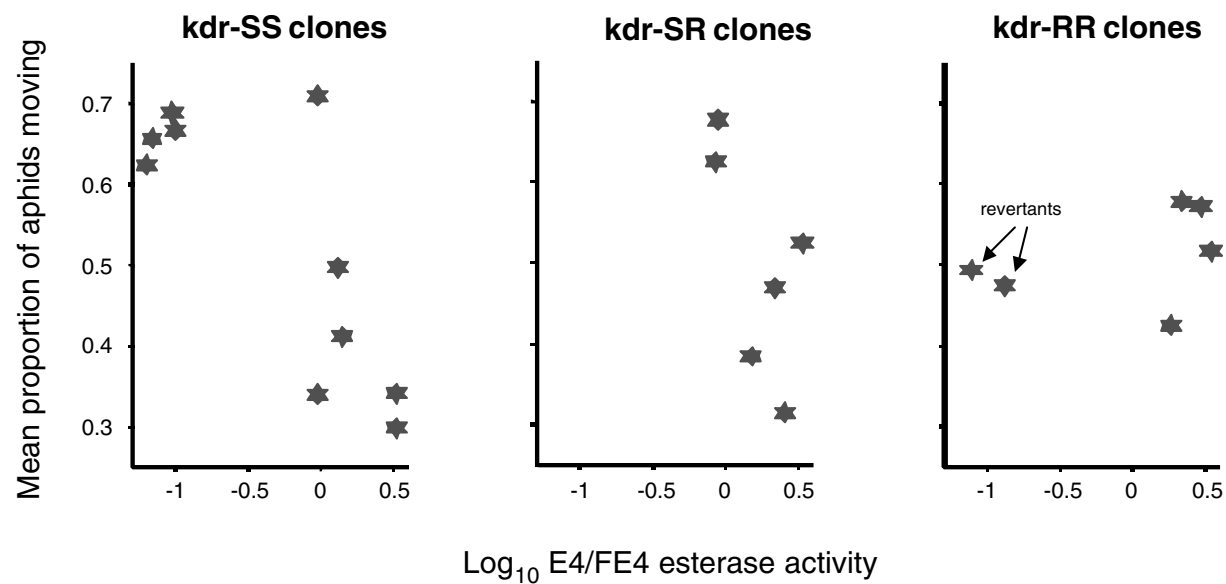

Figure 5 Predicted mean movement from deteriorating leaves of Myzus persicae clones with $k d r-S S$, -SR and -RR genotypes and esterase-S to $-\mathrm{R}_{3}$ levels.

Table 3 Response of housefly strains to $\mu \mathrm{g} / \mu \mathrm{l}$ topical applications of DDT

\begin{tabular}{lcccc}
\hline Strain & $n$ & $L D_{50}(95 \% \text { confidence limits })^{\mathrm{a}}$ & Slope & $R F$ \\
\hline Cooper & 247 & $0.07(0.05-0.11) \mathrm{a}$ & 1.5 & 1 \\
USA1 & 212 & $0.03(0.01-0.05) \mathrm{a}$ & 1.1 & 0.4 \\
USA2 & 272 & $0.33(0.20-0.54) \mathrm{b}$ & 1.1 & 5 \\
690ab & 222 & $0.08(0.05-0.12) \mathrm{a}$ & 1.5 & 1 \\
579 & 248 & $0.51(0.30-0.76) \mathrm{b}$ & 1.7 & 7 \\
530 & 241 & $3.15(2.03-5.12) \mathrm{c}$ & 1.3 & 43 \\
213ab & 278 & $1.03(0.64-1.63) \mathrm{b}$ & 1.0 & 14 \\
\hline
\end{tabular}

avalues followed by a different letter denote nonoverlap of $95 \%$ CLs $(P<0.05)$

propensity to move to fresh leaves. This suggests some association between behaviour and the esterase genotype rather than the phenotype.

\section{Bioassays on $M$. domestica}

The seven housefly strains could be divided into two groups on the basis of their collective responses to deltamethrin and DDT. Three strains: 213ab, 530, and 579 exhibited resistance to both DDT (resistance factors of 14, 43, and 7, respectively) and deltamethrin (resistance factors of 105, 497, and 14, respectively). Four strains: Cooper, 690ab, USA1, and USA2 were fully susceptible to one or both compounds (Tables 3 and 4). Consistent with these results, the latter four strains were all confirmed as wild type for their domain II sodium channel sequences, whereas all three resistant strains contained the $k d r$ (L1014P) mutation, with two strains, 213ab and 530, also carrying the super- $k d r$ (M918 T) mutation. Previous studies have shown that the $k d r$ mutation is associated with moderate (5 to 30 -fold) levels of resistance to DDT and pyrethroids, whereas the additional presence of the super- $k d r$ mutation increases resistance to over 100 -fold for the more potent type II pyrethroids such as deltamethrin (Williamson et al, 1996). The USA2 and 690ab strains, showing an inconsistent response to DDT and deltamethrin, probably possessed a metabolic resistance mechanism specific to either DDT or pyrethroids.
Table 4 Response of housefly strains to $\mathrm{ng} / \mu \mathrm{l}$ topical applications of deltamethrin

\begin{tabular}{lcclc}
\hline Strain & $n$ & $L D_{50}(95 \% \text { confidence limits })^{a}$ & Slope & $R F$ \\
\hline Cooper & 226 & $0.2(0.1-0.3) \mathrm{a}$ & 1 & 1 \\
USA1 & 134 & $0.5(0.2-1.0) \mathrm{a}$ & 1.1 & 2.5 \\
USA2 & 169 & $0.6(0.2-1.2) \mathrm{a}$ & 0.9 & 3 \\
690ab & 172 & $2.8(1.4-5.1) \mathrm{b}$ & 1 & 14 \\
579 & 189 & $2.7(1.4-5.0) \mathrm{b}$ & 1 & 14 \\
530 & 186 & $99.4(55.3-174.4) \mathrm{c}$ & 1.1 & 497 \\
213ab & 173 & $20.9(6.6-41.9) \mathrm{d}$ & 1.2 & 105 \\
\hline
\end{tabular}

aValues followed by a different letter denote nonoverlap of 95\% CLs $(P<0.05)$.

Temperature gradient studies on $M$. domestica

The majority of individuals (82-94\%) of all four strains lacking $k d r$ had, within $20 \mathrm{~min}$, settled between temperatures of 26.5 and $29^{\circ} \mathrm{C}$ in the warmest quarter of the gradient (Figure 6a). Conversely, those containing sodium channel mutations (Figure 6b) exhibited no positional preference $(20-25 \%$ in the warmest quarterthe fraction that would be expected if individuals had distributed themselves randomly). A generalised linear model showed that slopes of the lines fitted to the two groups of flies ( $k d r$ and non- $k d r$ ) were significantly different from each other $\left(F_{1,80}=17.93, P<0.001\right)$ as a result of an increasing number of non- $k d r$ flies moving to the warmer part of the temperature gradient. The intercepts were similar $\left(F_{1,80}<3.84, P>0.05\right)$ because, at the beginning of each observation, flies were introduced at the centre of the temperature gradient.

\section{Discussion}

Intuitively, some types of resistance mechanism are more likely to confer fitness disadvantages than others. Attempts to review the relations between fitness and resistance mechanism (Roush and McKenzie, 1987) concluded that mechanisms based on the overproduction of detoxifying enzymes (eg carboxylesterases) often lead to serious disadvantages whereas $k d r$-type mechanisms of pyrethroid resistance may confer little or no effect on 

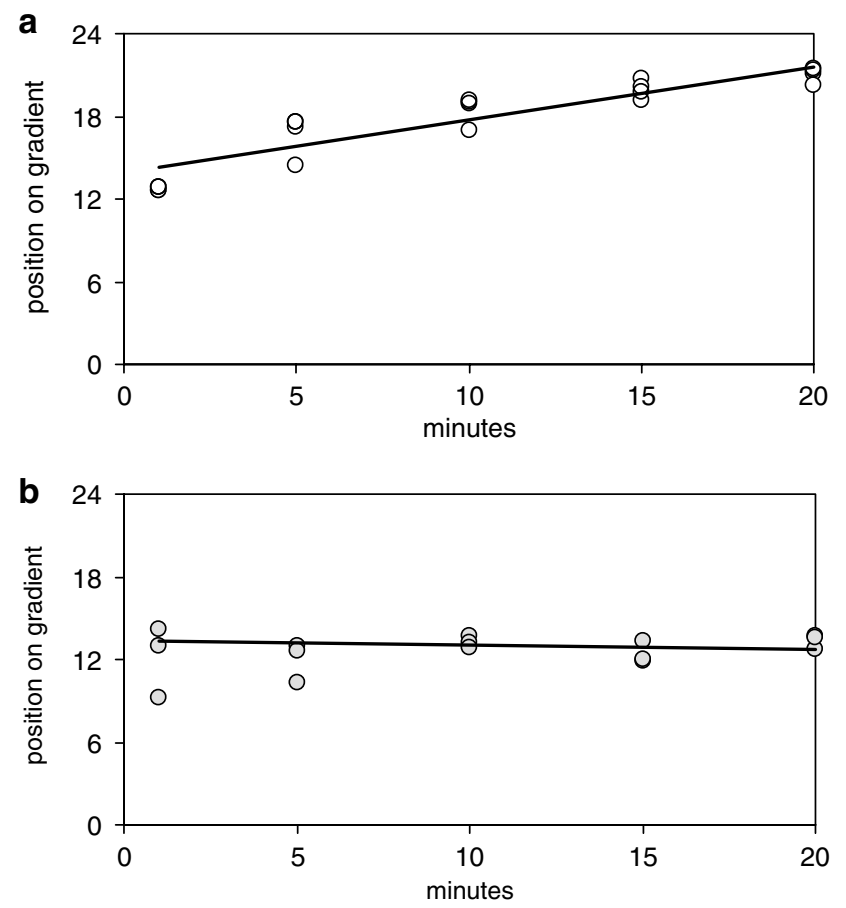

Figure 6 Responses of (a) the four strains without $k d r / s u p e r-k d r$ mutations and (b) the three strains with $k d r /$ super-kdr mutations on exposure to a $19-29^{\circ} \mathrm{C}$ temperature gradient $(0-24 \mathrm{~cm})$. Each point represents the mean response of a single housefly strain, the collective movement of which is charted over a $20 \mathrm{~min}$ period.

overall fitness. The results of our study concur with this conclusion in that genotypes conferring high carboxylesterase titres were shown, in aphids, to be associated with an inability to move from senescing leaves at low temperature. However, work on the behavioural correlates of resistance genotypes in both aphids and houseflies suggests that $k d r$ mutations are also associated with detrimental behaviour.

Our study confirms earlier reports of biological and behavioural effects associated with high levels of carboxylesterase resistance in $M$. persicae (Foster et al, 1996, 1997), but the use of clones differing in both esterase titre and $k d r$ genotype enabled a clearer resolution for the role of each mechanism in influencing responsiveness to environmental cues (either leaf deterioration or the presence of alarm pheromone). Increased esterase production was significantly associated with reduced movement from deteriorating leaves. A possible explanation of this and other side effects of esterase resistance in $M$. persicae is the large investment of resources in carboxylesterase production which in the most resistant $\left(\mathrm{R}_{3}\right)$ clones account for ca. 3\% of the total body protein (Devonshire and Moores, 1982). It has been shown that such high carboxylesterase titres reflect a proportionate increase in gene copy number, rising to approximately 80 copies of either E4 or FE4 in $\mathrm{R}_{3} M$. persicae (Field et al, 1999).

Interestingly, esterase-revertant clones, carrying large numbers of unexpressed esterase genes, did not affiliate with true esterase-susceptible forms but instead showed similar responses, to alarm pheromone and leaf deterioration, to clones expressing high levels of esterase. This suggests that reduced response in this case was not directly related to phenotypic esterase overproduction, but rather to the presence of amplified carboxylesterase genes. It is worth noting that the $k d r$ genotype was not associated with reduced movement from deteriorated leaves. This may reflect the complexity of the behavioural response in this instance. Mutations such as $k d r$, with direct effects upon nerve function, may be more likely to disrupt the perception of simple stimuli such as temperature or pheromones. Dispersal from deteriorating leaves, however, is probably a more intricate response dependent upon complex stimuli, and so may be less obviously associated with nerve function.

In a prior study (Foster et al, 1999), showing a correlated response to alarm pheromone with the presence or absence of $k d r$, only a single dose of alarm pheromone was used and those clones utilised did not display the same range of genotypes, nor were they as well characterised as the current subset. In the current study, the proportion of aphids disturbed by the presence of alarm pheromone increased with stimulus concentration for all three $k d r$ genotypes, but there were clear differences between them. Heterozygotes ( $k d r$-SR) were less responsive than homozygous susceptible forms ( $k d r-S S)$, and $k d r$-RR forms were least responsive of all. Once adjusted, statistically, for the presence of $\mathrm{kdr}$, response to alarm pheromone was also inversely associated with carboxylesterase titres; with $\mathrm{R}_{3}$ aphids showing a lower response than $\mathrm{R}_{2}$ forms. An esteraserevertant clone (794J-rev) showed a response similar to the $\mathrm{R}_{3}$ clone from which it was derived. Although both possess the esterase- $R_{3}$ genotype, only the nonrevertant clone (794J) expressed this enzyme, implying that it is the genotype to which the pheromone response is allied, and not the phenotype. This reduced response to alarm pheromone is likely to be a highly maladaptive behaviour, as the dispersal of aphids in response to this stimulus is considered to be an important behavioural adaptation for avoiding attack by natural enemies (Pickett et al, 1992)

Of the M. domestica strains used in this study, 213ab, 530, and 579 were confirmed as carrying $k d r$ and/or super- $k d r$ mutations and, as expected, this correlated with phenotypic resistance to both DDT and deltamethrin. The other four strains were susceptible to at least one of these compounds, and did not carry the $k d r$ mutation. Our $\mathrm{LD}_{50}$ values for the strains Cooper 530 and 579 compare favourably with figures published previously. Farnham et al (1987) showed that $k d r$ alone conferred 17- and 34-fold resistance to DDT and deltamethrin and 63- and 221-fold resistance, respectively, when super- $k d r$ was also present. Our data showed 7- and 13-fold resistance conferred by $k d r$ alone to DDT and deltamethrin, and 45- and 497-fold resistance, respectively with the addition of the super-kdr mutation. These mechanisms are therefore clearly stable in unselected laboratory populations.

The differential temperature preference shown by the $k d r$ and non- $k d r$ groups of flies strongly suggests an association between the presence of insecticide-resistant sodium channels and the perception of (or at least the response to) temperature gradients. It is worth noting that the genetic background of the strains 530 and 579 was extremely similar to that of the Cooper strain, having undergone a considerable programme of backcrossing in order to homogenise the genetic background in which the $k d r$ and super-kdr genes existed (Farnham 
et al, 1987). The majority of individuals of all four $k d r$ susceptible strains had, within $20 \mathrm{~min}$, moved to the warmest quarter of the gradient. Conversely, those carrying $k d r$ and/or super- $k d r$ sodium channel mutations exhibited no positional preference. It is difficult to assess whether this lack of preference is maladaptive, but if it represents a reduced ability to seek out optimal temperatures, then $k d r$ strains will suffer decreased longevity, fecundity, and ovarian development rates. All these parameters are affected by temperature in houseflies (Elvin and Krafsur, 1984; Fletcher et al, 1990; Lysyk, 1991a, b).

In pest-management terms, the pleiotropic effects described above clearly have the potential to exert a large influence on the selection and dynamics of genes conferring insecticide resistance. Such influences will be most obvious in the absence of selection pressure by insecticides and under stressful environments. It is therefore of note that the incidence of $\mathrm{R}_{2}$ and $\mathrm{R}_{3} M$. persicae aphids in the UK decreases over the winter period when insecticidal selection pressure is relaxed, but that the proportion of $k d r$-resistant genotypes in the population has appeared to remain stable in recent years, perhaps reflecting the high amount of pyrethroid use (Foster et al, 2002). In northern Europe, $k d r$ is the major mechanism of pyrethroid resistance in houseflies (Keiding, 1999). In Danish piggeries, resistance to pyrethroids is increasingly common, and this may reflect the near continuous selection pressure exerted in these environments (Kristensen et al, 2001). We are unaware of any attempts to monitor the frequency of $k d r$ alleles in areas where pyrethroid use is decreasing.

The results presented above show that although the mechanisms that mediate the reduced responses to both leaf deterioration and alarm pheromone in insecticideresistant $M$. persicae, and differential movement in response to a temperature gradient in $M$. domestica remain equivocal, there is increasingly sound evidence that they are pleiotropic effects of genes coding for insecticide resistance. In the case of the $k d r$ sodium channel mutation specifically, this conclusion is strengthened by evidence that explicitly links qualitative and quantitative changes in the sodium channel structural gene para (paralytic) in Drosophila melanogaster to behavioural disturbances. For example, the temperature-sensitive paralysis exhibited by individuals carrying the point mutation $n a p^{t s}$ (no action potential, temperature sensitive) results from a reduction in the expression of the para gene. It is thought that, when temperature rises, an increasing fraction of the available sodium channels is required to maintain propagation of action potentials. Thus, when sodium channel expression is decreased, the number of available channels cannot meet the demands of elevated temperature (Kernan et al, 1991). The mutation tipE (temperature-induced paralysis locus E) also disrupts para expression and confers temperatureinduced paralysis as a result of a decrease in sodium channel numbers (Feng et al, 1995) The sbl (smellblind) mutation, which is not temperature sensitive, is also an allele of the para gene (Lilly et al, 1994). This associates sodium channel mutations with olfactory and chemotactic defects (Lilly and Carlson, 1990) and with changes in sexual behaviour (Tompkins et al, 1982, 1983). In another unrelated point mutation conferring resistance to the cyclodienes, a mutation in the structural gene encoding the $\gamma$-aminobutyric acid receptor ( $r d l$ or resistance to dieldrin) also appears to induce reversible temperaturesensitive paralysis (Ffrench-Constant et al, 2000).

Studies on $k d r /$ super-kdr mutations incorporated into the insect para gene and expressed in vitro using Xenopus oocytes have revealed that these mutations reduce the sensitivity of the channel protein to pyrethroids and DDT and therefore confer resistance. Such mutations almost certainly have the same function in aphids, houseflies, and in all other insects in which they occur (Vais et al, 2001). However, in addition to making the channel protein less sensitive to some insecticides, these mutations also alter the normal gating properties of the sodium channel. This causes an elevation in their action potential threshold that, in vivo, would cause a general reduction in the excitability of the nervous system (Smith et al, 1997; Vais et al, 1997; Lee et al, 1999; Vais et al, 1997), and is likely to cause changes in the way that resistant individuals respond to external stimuli.

Such behavioural associations have wider implications beyond that of the sustainability of pest-management strategies alone. There is currently a debate over whether the pleiotropic effects of adaptive mutations can contribute to assortative mating and, therefore, speciation (Dieckmann and Doebeli, 1999; Emelianov et al, 2001). If the collective influence of genes conferring insecticide resistance on behavioural attributes, such as short- or long-range dispersal, can contribute to assortative mating between insects, it is possible that the pleiotropic effects of insecticide resistance might promote wider genetic differentiation than that which occurs at resistance loci alone.

\section{Acknowledgements}

We thank James Campbell, Diana Cox, Barbara Hackett, and Neil Mason for their expert technical assistance, and Robin Thompson and Alan Todd for help with statistical analysis. SP Foster was supported by a SAPPIO-Link project (Sustainable Arable Protection through Precision Input Optimisation) secured by Alan Devonshire. This involved the Department of Environment, Food and Rural Affairs, Agrovista UK Ltd, the British Potato Council, QV Foods Ltd and Syngenta. Rothamsted Research receives grant-aided support from the Biotechnology and Biological Sciences Research Council.

\section{References}

Alyokhin AV, Ferro DN (1999). Relative fitness of Colorado potato beetle (Coleoptera: Chrysomelidae) resistant and susceptible to the Bacillus thuringiensis Cry3A toxin. J Econ Entomol 92: 510-515.

Baker JE, Perezmendoza J, Beeman RW, Throne JE (1998). Fitness of a malathion-resistant strain of the parasitoid Anisopteromalus calandrae (Hymenoptera: Pteromalidae). J Econ Entomol 91: 50-55.

Bloch G, Wool D (1994). Methidathion resistance in the sweetpotato whitefly (Aleyrodidae: Homoptera) in Israel: selection, heritability, and correlated changes of esterase activity. J Econ Entomol 87: 1147-1156.

Boivin TC, Chabert D'hieres JC, Bouvier D, Beslay, Sauphanor B (2001). Pleiotropy of insecticide resistance in the codling moth, Cydia pomonella. Entomol Exp Appl 99: 381-386. 
Boots M, Begon M (1993). Trade-offs with resistance to a granulosis virus in the Indian meal moth, examined by a laboratory evolution experiment. Funct Ecol 7: 528-534.

Brewer MJ, Mornhinweg DW, Huzurbazar S (1999). Compatibility of insect management strategies: Diuraphis noxia abundance on susceptible and resistant barley in the presence of parasitoids. Biocontrol 43: 479-491.

Brewer MJ, Trumble JT (1991). Inheritance and fitness consequences of resistance to fenvalerate in Spodoptera exigua (Lepidoptera, Noctuidae). J Econ Entomol 84: 16381644

Carriere Y, Deland JP, Roff DA, Vincent C (1994). Life-history costs associated with the evolution of insecticide resistance. Proc R Soc Lond Ser B-Biol Sci 258: 35-40.

Carriere Y, Ellers-Kirk C, Patin AL, Sims MA, Meyer S, Liu YB et al (2001). Overwintering cost associated with resistance to transgenic cotton in the pink bollworm (Lepidoptera: Gelechiidae). J Econ Entomol 94: 935-941.

Carriere Y, Roff DA, Deland JP (1995). The joint evolution of diapause and insecticide resistance-a test of an optimality model. Ecology 76: 1497-1505.

Charpentier A, Fournier D (2001). Levels of total acetylcholinesterase in Drosophila melanogaster in relation to insecticide resistance. Pestic Biochem Physiol 70: 100-107.

Chevillon C, Bourguet D, Rousset F, Pasteur N, Raymond M (1997). Pleiotropy of adaptive changes in populations: comparisons among insecticide resistance genes in Culex pipiens. Genet Res 70: 195-203.

Crow JF (1957). Genetics of resistance to chemicals. Annu Rev Entomol 2: 227-246.

Devonshire AL, Moores GD (1982). A carboxylesterase with broad substrate specificity causes organophosphorus, carbamate and pyrethroid resistance in peach-potato aphids (Myzus persicae). Pestic Biochem Physiol 18: 235-246.

Devonshire AL, Moores GD, Ffrench-Constant RH (1986). Detection of insecticide resistance by immunological estimation of carboxylesterase activity in Myzus persicae (Sulzer) and cross reaction of the antiserum with Phorodon humuli (Schrank) (Hemiptera: Aphididae). Bull Entomol Res 76: 97107.

Dieckmann U, Doebeli M (1999). On the origin of species by sympatric speciation. Nature 400: 354-357.

Elvin MK, Krafsur ES (1984). Relationship between temperature and rate of ovarian development in the housefly, Musca domestica L (Diptera, Muscidae). Ann Entomol Soc Am 77: 5055.

Emelianov I, Dres M, Baltensweiler W, Mallet J (2001). Hostinduced assortative mating in host races of the larch budmoth. Evolution 55: 2002-2010.

Farnham AW, Murray AWA, Sawicki RM, Denholm I, White JC (1987). Characterization of the structure activity relationship of $\mathrm{kdr}$ and 2 variants of super-kdr to pyrethroids in the housefly (Musca domestica L.). Pestic Sci 19: 209-220.

Feng GP, Deak P, Kasbekar DP, Gil DW, Hall LM (1995). Cytogenetic and molecular localization of tipe-a gene affecting sodium-channels in Drosophila melanogaster. Genetics 139: $1679-1688$.

Ffrench-Constant RH, Anthony N, Aronstein K, Rocheleau T, Stilwell G (2000). Cyclodiene insecticide resistance: from molecular to population genetics. Annu Rev Entomol 45: 449466.

Field LM, Blackman RL, Tylersmith C, Devonshire AL (1999). Relationship between amount of esterase and gene copy number in insecticide-resistant Myzus persicae (Sulzer). Biochem I 339: 737-742.

Field LM, Devonshire AL, Ffrench-Constant RH, Forde BG (1989). Changes in DNA methylation are associated with loss of insecticide resistance in the peach-potato aphid Myzus persicae (Sulz). FEBS Lett 243: 323-327.

Field LM, Devonshire AL, Forde BG (1988). Molecular evidence that insecticide resistance in peach-potato aphids (Myzus persicae Sulz.) results from amplification of an esterase gene. Biochem J 251: 309-312.

Fletcher MG, Axtell RC, Stinner RE (1990). Longevity and fecundity of Musca domestica (Diptera, Muscidae) as a function of temperature. J Med Entomol 27: 922-926.

Follett PA, Gould F, Kennedy GG (1993). Comparative fitness of 3 strains of colorado potato beetle (Coleoptera, Chrysomelidae) in the field - spatial and temporal variation in insecticide selection. J Econ Entomol 86: 1324-1333.

Foster SP, Harrington R, Devonshire AL, Denholm I, Clark SI, Mugglestone MA (1997). Evidence for a possible fitness trade-off between insecticide resistance and the low temperature movement that is essential for survival of UK populations of Myzus persicae (Hemiptera: Aphididae). Bull Entomol Res 87: 573-579.

Foster SP, Harrington R, Devonshire AL, Denholm I, Devine GJ Kenward MG et al (1996). Comparative survival of insecticide-susceptible and resistant peach-potato aphids, Myzus persicae (Sulzer) (Hemiptera: Aphididae), in low temperature field trials. Bull Entomol Res 86: 17-27.

Foster SP, Harrington R, Dewar AM, Denholm I, Devonshire AL (2002). Temporal and spatial dynamics of insecticide resistance in Myzus persicae (Hemiptera: Aphididae). Pest Manag Sci 58: 895-907.

Foster SP, Woodcock CM, Williamson MS, Devonshire AL, Denholm I, Thompson R (1999). Reduced alarm response by peach-potato aphids, Myzus persicae (Hemiptera: Aphididae), with knock-down resistance to insecticides (kdr) may impose a fitness cost through increased vulnerability to natural enemies. Bull Entomol Res 89: 133-138.

Groeters FR, Tabashnik BE, Finson N, Johnson MW (1993) Resistance to Bacillus thuringiensis affects mating success of the diamondback moth (Lepidoptera, Plutellidae). J Econ Entomol 86: 1035-1039.

Guillemaud T, Lenormand T, Bourguet D, Chevillon C, Pasteur N, Raymond M (1998). Evolution of resistance in Culex pipiens: allele replacement and changing environment. Evolution 52: 443-453.

Haubruge E, Arnaud L (2001). Fitness consequences of malathion-specific resistance in red flour beetle (Coleoptera: Tenebrionidae) and selection for resistance in the absence of malathion. I Econ Entomol 94: 552-557.

Hollingsworth RG, Tabashnik BE, Johnson MW, Messing RH, Ullman DE (1997). Relationship between susceptibility to insecticides and fecundity across populations of cotton aphid (Homoptera: Aphididae). J Econ Entomol 90: 55-58.

Keiding J (1999). Review of the global status and recent development of insecticide resistance in field populations of the housefly, Musca domestica (Diptera: Muscidae). Bull Entomol Res: Suppl Ser 89: S1-S67.

Kernan MJ, Kuroda MI, Kreber R, Baker BS, Ganetzky B (1991). Napts, a mutation affecting sodium-channel activity in Drosophila, is an allele of Mle, a regulator of X-chromosome transcription. Cell 66: 949-959.

Kristensen M, Spencer AG, Jespersen JB (2001). The status and development of insecticide resistance in Danish populations of the housefly Musca domestica L. Pest Manag Sci 57: 8289.

Lee SH, Smith TJ, Knipple DC, Soderlund DM (1999). Mutations in the house fly Vssc1 sodium channel gene associated with super-kdr resistance abolish the pyrethroid sensitivity of $V$ ssc1/tipE sodium channels expressed in Xenopus oocytes. Insect Biochem Mol Biol 29: 185-194.

Lilly M, Carlson J (1990). Smellblind - a gene required for Drosophila olfaction. Genetics 124: 293-302.

Lilly M, Kreber R, Ganetzky B, Carlson JR (1994). Evidence that the Drosophila olfactory mutant smellblind defines a novel class of sodium-channel mutation. Genetics 136: 1087-1096.

Lysyk TJ (1991a). Effects of temperature, food, sucrose feeding on longevity of the house-fly (Diptera, Muscidae). Environ Entomol 20: 1176-1180. 
Lysyk TJ (1991b). Modelling oviposition of the house-fly (Diptera, Muscidae). Can Entomol 123: 345-352.

Martinez-Torres D, Foster SP, Field LM, Devonshire AL, Williamson MS (1999). A sodium channel point mutation is associated with resistance to DDT and pyrethroid insecticides in the peach-potato aphid, Myzus persicae (Sulzer) (Hemiptera: Aphididae). Insect Mol Bio 8: 339-346.

Mason PL (1998). Selection for and against resistance to insecticides in the absence of insecticide: a case study of malathion resistance in the saw-toothed grain beetle, Oryzaephilus surinamensis (Coleoptera: Silvanidae). Bull Entomol Res 88: 177-188.

McKenzie JA (1993). Measuring fitness and intergenic interactions - the evolution of resistance to diazinon in Lucilia cuprina. Genetica 90: 227-237.

McKenzie JA (1996). Ecological and Evolutionary Aspects of Insecticide Resistance. Academic Press: London.

McKenzie JA, O'farrell K (1993). Modification of developmental instability and fitness - malathion-resistance in the Australian sheep blowfly, Lucilia cuprina. Genetica 89: 67-76.

Minkoff C, Wilson TG (1992). The competitive ability and fitness components of the methoprene-tolerant (met) Drosophila mutant resistant to juvenile-hormone analog insecticides. Genetics 131: 91-97.

Moores GD, Devine GJ, Devonshire AL (1994). Insecticideinsensitive acetylcholinesterase can enhance esterase-based resistance in Myzus persicae and Myzus nicotianae. Pestic Biochem Physiol 49: 114-120.

Omer AD, Leigh TF, Granett J (1992). Insecticide resistance of greenhouse-whitefly (Homoptera, Aleyrodidae) and fitness on plant hosts relative to the San-Joaquin valley (California) cotton agroecosystem. J Appl Entomol-Z Angew Entomol 113: 244-251.

Oppert B, Hammel R, Throne JE, Kramer KJ (2000). Fitness costs of resistance to Bacillus thuringiensis in the Indian meal moth, Plodia interpunctella. Entomol Exp Appl 96: 281-287.

Pickett JA, Wadhams LJ, Woodcock CM, Hardie J (1992). The chemical ecology of aphids. Annu Rev Entomol 37: 67-90.

Roush RT, Mckenzie JA (1987). Ecological genetics of insecticide and acaricide resistance. Annu Rev Entomol 32: 361-380.

Rowland M (1991a). Activity and mating competitiveness of gamma $\mathrm{HCH} /$ dieldrin resistant and susceptible male and virgin female Anopheles gambiae and An. stephensi mosquitoes, with assessment of an insecticide-rotation strategy. Med Veterinary Entomol 5: 207-222.

Rowland M (1991b). Behaviour and fitness of gamma $\mathrm{HCH} /$ dieldrin resistant and susceptible female Anopheles gambiae and An. stephensi mosquitoes in the absence of insecticide. Med Veterinary Entomol 5: 193-206.

Smith TJ, Lee SH, Ingles PJ, Knipple DC, Soderlund DM (1997). The L1014F point mutation in the house fly Vssc1 sodium channel confers knockdown resistance to pyrethroids. Insect Biochem Mol Biol 27: 807-812.

Tang JD, Collins HL, Roush RT, Metz TD, Earle ED, Shelton AM (1999). Survival, weight gain, and oviposition of resistant and susceptible Plutella xylostella (Lepidoptera: Plutellidae) on broccoli expressing CrylAc toxin of Bacillus thuringiensis. J Econ Entomol 92: 47-55.

Tang JD, Gilboa S, Roush RT, Shelton AM (1997). Inheritance, stability, lack-of-fitness costs of field-selected resistance to Bacillus thuringiensis in diamondback moth (Lepidoptera: Plutellidae) from Florida. I Econ Entomol 90: 732-741.

Tompkins L, Gross AC, Hall JC, Gailey DA, Siegel RW (1982). The role of female movement in the sexual behavior of Drosophila melanogaster. Behav Genet 12: 295-307.

Tompkins L, Siegel RW, Gailey DA, Hall JC (1983). Conditioned courtship in Drosophila and its mediation by association of chemical cues. Behav Genet 13: 565-578.

Vais H, Williamson MS, Devonshire AL, Usherwood PNR (2001). The molecular interactions of pyrethroid insecticides with insect and mammalian sodium channels. Pest Manag Sci 57: 877-888.

Vais H, Williamson MS, Goodson SJ, Devonshire AL, Warmke JW, Usherwood PNR et al (2000). Activation of Drosophila sodium channels promotes modification by deltamethrin reductions in affinity caused by knock-down resistance mutations. J General Physiol 115: 305-318.

Vais H, Williamson MS, Hick CA, Eldursi N, Devonshire AL, Usherwood PNR (1997). Functional analysis of a rat sodium channel carrying a mutation for insect knock-down resistance (kdr) to pyrethroids. FEBS Lett 413: 327-332.

White NDG, Bell RJ (1995). A malathion resistance gene associated with increased life-span of the rusty grain beetle, Cryptolestes ferrugineus (Coleoptera, Cucujidae). J Gerontol Ser A-Biol Sci Med Sci 50: B9-B13.

Williamson MS, Martinez-Torres D, Hick CA, Devonshire AL (1996). Identification of mutations in the housefly para-type sodium channel gene associated with knockdown resistance (kdr) to pyrethroid insecticides. Mol General Genet 252: 51-60.

Yamamoto A, Yoneda H, Hatano R, Asada M (1995). Influence of hexythiazox resistance on life-history parameters in the citrus red mite, Panonychus citri (McGregor). J Pestic Sci 20: 521-527. 